Seaman, G. R. (1963). Ann. N.Y. Acad. Sci. 102, 717.

Shaffer, J. G. \& Frye, W. W. (1948), Amer. F. Hyg. 47, 2 I 4.

Shaffer, J. G., Key, I. D. \& McDade, J. J. (1960). Bact. Proc. p. 58.

Shaffer, J. G. \& Sienkiewicz, H. S. (1952). Science, 116, 306.

Welch, C. S., Wakefield, E. G. \& Adams, M. (1936). Arch. intern. Med. 58, 1095.

Williams, P. P., Davis, R. E., Doetsch, R. N. \& Gutierrez, J. (196r). Appl. Microbiol. 9, 405.

Williams, P. P., Gutierrez, J. \& Davis, R. E. (1963). Appl. Microbiol. I1, 260.

\title{
The nutrition of the micro-aerophilic pathogen Actinomyces israelii
} By J. W. Porteous, Department of Biological Chemistry, Marischal College, University of Aberdeen

Micro-organisms have become well-established tools for research in the field of nutrition for reasons which are on the one hand of a purely technical and on the other of a biological nature. Technically micro-organisms are generally more readily grown in well-defined environmental conditions, their 'diet' is more readily controlled, the organisms themselves more readily handled and analysed than other biological forms. In biological terms micro-organisms offer the advantages of a relatively simple undifferentiated cell structure and, within the minute volume of a single cell, a large selection if not all of the biochemical activities typical of highly differentiated organisms such as plants and animals. Moreover, many microorganisms have been shown to respond to changes in environmental conditions through feedback mechanisms (including inhibition, induction and repression mechanisms) which are now well documented (Frisch, I96r; Riley \& Pardee, 1962) and some of which offer a partial explanation of metabolic regulation in organisms of greater cellular and organ complexity (Krebs, 1956; Knox, Auerbach \& Lin, I956; Wolstenholme \& O'Connor, 1959; Frisch, 196r; Allen, 1962; Weber, 1963; Pontecorvo, 1963). The fairly ready isolation of mutant micro-organisms derived from parent cells with known activities has helped in the elucidation of some aspects of intracellular control of metabolism (e.g. Jacob \& Monod, I96r; Monod \& Jacob, I96I), promoted inquiry into the detailed structure of genes (Demerec \& Hartman, I959; Pontecorvo, 1963) and helped to elucidate metabolic pathways and nutritional patterns (Davis, 1955; DeBusk, 1956).

It is nevertheless as well to realize that relatively few genera of micro-organisms have been used in the acquisition of this detailed insight into various aspects of biochemistry. In almost every instance the nutritional requirements of the test organism have been relatively simple and were known before the other knowledge was or could be acquired (Lichstein, I960). It may therefore be of some interest to recall aspects of work with an organism whose nutritional requirements and metabolic activities were, until recently, unknown. The reasons for this lack of knowledge were of a purely technical nature; it is the prime purpose of this paper to outline the methods used in determining the nutritional requirements of this micro-organism. It remains to be seen whether the detailed biochemistry of the organism fits the tentative predictions made from a knowledge of its nutritional requirements and is consistent with that outlined for organisms which, generally speaking, survive on simpler nutrient media. 
Actinomyces israelii is a Gram-positive, filamentous, micro-aerophilic or anaerobic bacterium pathogenic to man and possibly some other animals (Erikson, I940, I953; Erikson \& Porteous, I953, I955) and occurs frequently in the oral cavity of man; the significance of this occurrence is not known (Howell, Stephan \& Paul, 1962). The organism ordinarily grows slowly and invariably forms coherent, discrete, white pellicles, $0.5^{-2.5} \mathrm{~mm}$ in diam., which grow at the bottom of vessels of liquid medium, the medium itself remaining clear at all stages of growth of the organism (Erikson \& Porteous, I953; Christie \& Porteous, I962a). Closely related to A. israelii by reason of morphology, habitat or pathogenicity are organisms of the family Actinoplanaceae and of the genera Nocardia, Thermoactinomyces, Micromonospora, Streptomyces, Mycococcus and Mycobacterium (Bergey, r957; Erikson, 1935, 1940, 1949, 1953; Jensen, 1953). Except for some members of the last genus there has never been any real difficulty in culturing these latter organisms in relatively simple, though not necessarily chemically defined, media. A. israelii, on the other hand, had until recently a long-established reputation as an organism which was particularly difficult to isolate in pure culture and peculiarly difficult to maintain in pure culture (see Christie \& Porteous, I962a). It was unfortunate that so many authors devised ever richer and more complex chemically undefined media in attempts to keep their $A$. israelii cultures viable, for Erikson \& Porteous (1953) showed that a simple broth medium was best suited to the routine maintenance of twelve recently isolated typical strains of the organism. Howell \& Pine (1956) made the first significant step towards the elucidation of the exact nutritional requirements of the organism when they showed that a complex but essentially chemically defined medium, originally devised for other purposes, would support thirteen species of anaerobic or microaerophilic Actinomyces in serial subculture; five of these strains were typical examples of A. israelii.

The pellicle-forming growth habit of $A$. israelii prohibits straightforward uniform inoculation of test media. Howell \& Pine (I956) passed the pellicles through a tissue grinder to obtain a fragmented cell suspension which provided uniform inocula and which in turn developed into typical pellicles. The strains available to Christie $\&$ Porteous ( 1960 ) could not be treated in this way; these authors developed instead a special culture technique which permitted uniform quantitative inoculation of test media. The filamentous structure of $A$. israelii precludes the use of cell-counting techniques as a measure of the growth of a culture, and the pellicle growth habit prohibits the measurement by the usual turbidimetric or nephelometric methods of the quantity of cell material formed during incubation; Howell \& Pine (I956) overcame this difficulty by drawing and expelling the growing pellicles through a sterile serological pipette at time intervals throughout the incubation period; the turbidity of the suspension was measured or alternatively the packed volume of the untreated pellicles. The latter method was used semi-quantitatively by Erikson \& Porteous (1953) but the former method was abandoned by Christie \& Porteous (1960, 1962a), who were forced to determine the total nitrogen content of the harvested pellicles in all their quantitative experiments. 
Preliminary experiments with the single strain (Wills) of $A$. israelii used throughout most of the work summarized here established four points:

(I) That suitable micro-aerophilic culture conditions could be obtained by sealing vessels of media with liquid paraffin.

(2) That two of the growth factors present in the Howell \& Pine (HP) medium (namely citrovorum factor (5-formyl-5, 6, 7, 8,- tetrahydropteroylglutamic acid) and coenzyme A) were not essential nutrients. Omission of these two growth factors from medium HP gave a medium subsequently referred to as medium $\mathrm{HP}_{\mathrm{I}}$.

(3) The optimum initial $\mathrm{pH}$ for growth of the organism was $7 \cdot 2$.

(4) There was a useful relationship between the amount of growth in the medium and the consequent change in the $\mathrm{pH}$ of the medium (Fig. $\mathrm{r}$ ). The $\mathrm{pH}$ value of the medium regularly fell from 7.0 to 5.5 during the period when growth was most

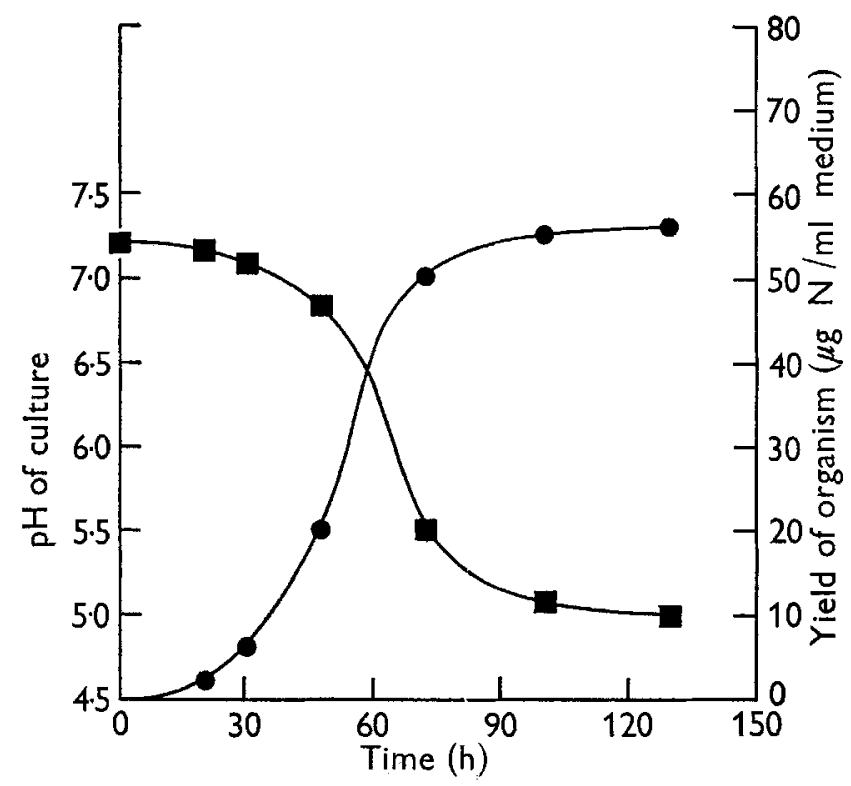

Fig. I. Changes in the $\mathrm{pH}$ value of medium HPI during growth of the Wills strain of Actinomyces israelii at $37^{\circ}$ under liquid paraffin seals. $\square, \mathrm{pH} ;-0$, growth (Christie \& Porteous, I962a).

Table $\mathbf{I}$. Calculated total nitrogen content of the major nitrogen-containing components of medium HP (Christie \& Porteous 1962a)

Component

Casein hydrolysate

$\left(\mathrm{NH}_{4}\right)_{2} \mathrm{SO}_{4}$

L-cysteine hydrochloride

Glutathione

Purine and pyrimidine bases

L-asparagine

L-tryptophan
Calculated

total nitrogen

content

( $\mu \mathrm{g} / \mathrm{ml}$ medium)

520*

212

90

68

32

21

5

* Determined experimentally on a separate stock solution of casein hydrolysate. 
rapid; this relationship was found to hold for all nutritionally adequate media subsequently devised. Accordingly, measurement of the $\mathrm{pH}$ of such media gave an immediate indication of the phase of growth of a culture. Such information was required in preparing inocula from a mother culture in a known phase of growth and occasionally to check that growth had ceased in a test medium.

For present purposes the composition of the Howell \& Pine medium may be described as a basal inorganic salts medium containing glucose, starch, glutathione, casein hydrolysate (supplemented with L-cysteine, L-tryptophan and L-asparagine), purines and pyrimidines (adenine, guanine, xanthine, thymine, uracil), eighteen growth factors, and ammonium sulphate. The contribution of the major nitrogencontaining components of the original Howell \& Pine medium to the total nitrogen content of the medium is shown in Table $\mathbf{I}$. The total nitrogen content of medium HP I $\left(94^{8} \mu \mathrm{g} \mathrm{N} / \mathrm{ml}\right)$ compared unfavourably with the maximum yield of cells obtained from it $(50-55 \mu \mathrm{g} \mathrm{N} / \mathrm{ml}$; Christie \& Porteous, $1962 a)$.

\section{Initial simplification of the Howell $\mathscr{\odot}$ Pine medium}

The nutritional requirement for each of the major nitrogen-containing components of medium HP was tested, in turn, by determining the growth curves for the organism in systematic modifications of medium $\mathrm{HP}_{\mathrm{I}}$; and the inoculum for each test medium was always grown in the simplest medium available at the time. Early experiments showed that ammonium sulphate was an unnecessary component of medium HPI; and that L-cysteine was an essential nutrient but that its initial concentration in the medium could be decreased from $1000 \mu \mathrm{g} / \mathrm{ml}$ to $200 \mu \mathrm{g} / \mathrm{ml}$ without affecting growth rates or final cell yields. These and many subsequent

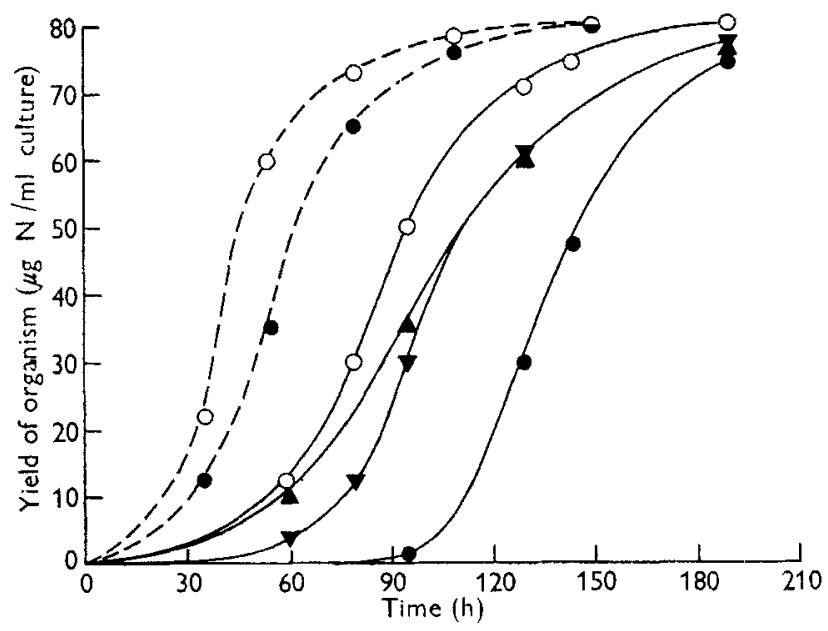

Fig. 2. Growth of the Wills strain of Actinomyces israelii at $37^{\circ}$ under liquid paraffin seals in $2 \mathrm{ml}$ of medium $\mathrm{HP}_{3}$ modified to contain various initial concentrations of glutathione $(\mu \mathrm{g} / \mathrm{ml}): 0,500$; $\mathbf{A}, 250 ; \boldsymbol{\nabla}, \mathbf{1 0 0} ; \mathbf{0}, 0 ;-$, growth of an inoculum taken from a stationary-phase mother culture; ......, growth of an inoculum taken from a rapidly growing mother culture (Christie \& Porteous, 1962a). 
results were obtained from examination of growth curves such as those shown in Fig. 2. The sigmoid growth curves indicate three phases of growth: an initial lag period followed by a period of rapid growth which is terminated by a stationary phase. It was apparent from the particular growth curves shown in Fig. 2 that glutathione was not a required component of the medium for the growth of $A$. israelii since the same stationary phase yield of cells and essentially the same maximum rates of growth were obtained whether glutathione was present in or absent from the test medium. But the lag period was accentuated if the inoculum was taken from a mother culture which had entered the stationary phase and further prolonged if glutathione was absent from the test medium. As a precaution, glutathione was retained in the medium at a diminished initial concentration of $100 \mu \mathrm{g} / \mathrm{ml}$. Further work of this kind showed that starch and the purines and pyrimidines were non-essential components of the original medium, that the casein hydrolysate could be replaced by appropriate L-amino acids and that L-tryptophan, like L-cysteine, was an essential nutrient for the organism. The resulting simplified medium HP6/B (Christie \& Porteous, I $962 a$ ) was chemically defined, contained only $65 \%$ of the total nitrogen of medium HPI and supported $45 \%$ more growth of $A$. israelii.

\section{The growth factor requirements of the Wills strain of A. israelii}

The next phase of the investigations involved elucidation of the growth factor requirements of the organism and for this purpose quantitative measurements of growth were abandoned in favour of visual assessments of the relative quantity and quality of growth in test media; such visual assessments were made with confidence after several months of experience with quantitative measurements and qualitative observations. The mother cultures for all experiments were prepared in medium HP6/B and uniform inocula dispensed into at least four tubes of each test medium. The test media consisted of medium HP6/B modified to contain only certain combinations of growth factors selected from the eighteen present in the original Howell $\&$ Pine medium. Subcultures were made every 5 days into four further tubes of fresh test medium. At the end of each 5-day growth period (cf. Fig. 2) the amount of growth was scored on a linear scale such that the inoculum scored I and the growth obtained in medium HP6/B itself scored 5 . As an additional aid a careful note was made of the appearance of the pellicles; typical coherent, discrete 'cauliflower' pellicles scored ' $T$ '. Experience had shown that slight contamination (Erikson \& Porteous, I955) or suboptimum growth conditions often produced detectable changes in the appearance of the pellicles; usually they became soft, slimy, or grossly swollen and 'puffy'; such pellicles scored ' $S$ '. Finally a note was made of the number of serial subcultures which the organism survived in each test medium. This tripartite semiquantitative visual scoring technique proved entirely adequate in demonstrating (Christie \& Porteous, 1962b) that only five growth factors (nicotinic acid, inositol, riboflavine, pyridoxal, biotin) of the eighteen present in the original Howell $\&$ Pine medium were required for vigorous growth of the single strain of $A$. israelii investigated, 


\section{Elucidation of amino acid requirements}

For the third phase of the work quantitative paper chromatography was used to discover which amino acids were most avidly assimilated from medium HP6/B by the growing cells of the same strain of $A$. israelii (Keir \& Porteous, 1962). Of the twenty amino acids present in medium HP6/B, six showed no change or increased slightly in concentration during growth of the organism; of the remaining fourteen amino acids, L-cysteine, which was already known to.be an essential nutrient, was the most avidly assimilated, followed closely by L-glutamic acid, L-serine and L-lysine (L-tryptophan was present in much smaller initial concentration than the other amino acids and was not determined, but had already been shown to be an essential nutrient). On the assumption that the most avidly assimilated amino acids were those that were most likely to be essential nutrients under conditions in which amino acids were the sole major nitrogenous components of the medium, attempts were made to grow the organism in medium HP6/B (which contained sixteen growth factors) modified to contain only the five L-amino acids tryptophan, cysteine, serine, glutamic acid and lysine. No growth was obtained in this medium and only limited growth occurred in a similar medium supplemented with L-leucine and L-isoleucine (the next two most avidly assimilated amino acids). Subsequent work showed that L-leucine and L-isoleucine were essential nutrients (Keir \& Porteous, I962), that L-lysine was also essential and that growth in the absence of $\mathrm{L}$-glutamate and L-serine was severely retarded (Porteous, unpublished).

\section{The minimum nutrient requirements of $\mathrm{A}$. israelii}

There seemed to be three possible reasons for the failure of the organism to grow in the two media just described, namely those containing only five or seven of the more avidly assimilated amino acids: (a) not all the required amino acid nutrients had been added to the media; (b) omission of thirteen or fifteen amino acids present in media HP and HP6/B now made one or more components of medium HP essential nutrients, whereas they had previously been non-essential (candidates for this role were ammonium sulphate and the purines and pyrimidines); (c) one or more of the superfluous growth factors present in medium HP6/B inhibited growth when the amino acid complement of this medium was depleted. These possibilities were tested (Keir \& Porteous, I962). The results of the tests are summarized in Tables 2 and 3. The media shown in these tables were all based on medium HP6/B (Christie \& Porteous, I 962a) which contained, inter alia, twenty amino acids and sixteen growth factors but no ammonium sulphate and no purines or pyrimidines. Comparison of the growth obtained in media $A$ and $A^{\prime}$ (Table 2) confirmed that ammonium sulphate was a non-essential component of the medium when a full complement of amino acids and growth factors was present; the same observation applied to growth in media $\mathrm{C}$ and $\mathrm{C}^{\prime}$ each of which contained only those five growth factors previously shown to be essential for growth of the organism. But when the amino acid complement was also depleted, omitting all but L-tryptophan, L-cysteine and the five next most avidly assimilated L-amino acids (serine, glutamic acid, lysine, leucine and isoleucine) 
ammonium sulphate became an essential component of the growth medium. Medium D (Table 2; Keir \& Porteous, I962) is the simplest chemically defined medium yet devised for the cultivation of any strain of $A$. israelii; it contained only $25 \%$ of the total nitrogen of medium HPI and consistently gave a $30 \%$ better yield of organism (Keir \& Porteous, 1962). In simple media of this kind it was possible for the first time to account quantitatively for the depletion of the $\alpha$-amino- and total-nitrogen content of the medium by the increase in cell nitrogen (Christie \& Porteous, 1962a).

Table 2. Maximum yields of Actinomyces israelii obtained from modifications of medium HP6/B (Keir Ë Porteous, 1962)

\begin{tabular}{|c|c|c|c|c|c|}
\hline \multirow[b]{2}{*}{ Medium } & \multicolumn{3}{|c|}{ Selected components* } & \multirow{2}{*}{$\begin{array}{l}\text { Total nitrogen } \\
\text { content of } \\
\text { medium }(\mu \mathrm{g} / \mathrm{ml})\end{array}$} & \multirow{2}{*}{$\begin{array}{c}\text { Maximum } \\
\text { cell yield } \\
(\mu \mathrm{g} \mathrm{N} / \mathrm{ml})\end{array}$} \\
\hline & $\begin{array}{l}\text { Amino } \\
\text { acids }\end{array}$ & $\begin{array}{l}\text { Growth } \\
\text { factors }\end{array}$ & $\begin{array}{l}\text { Ammonium } \\
\text { sulphate }\end{array}$ & & \\
\hline$A^{\prime}$ & 20 & I 6 & - & 613 & 70 \\
\hline A & 20 & 16 & + & 655 & 80 \\
\hline $\mathrm{C}^{\prime}$ & 20 & 5 & - & 613 & 70 \\
\hline C & 20 & 5 & + & 655 & 70 \\
\hline $\mathrm{D}^{\prime}$ & 7 & 5 & - & 198 & $0-10$ \\
\hline $\mathrm{D}$ & 7 & 5 & + & 240 & 70 \\
\hline
\end{tabular}

*The twenty amino acids and sixteen growth factors were those present in medium HP6/B (Christie $\&$ Porteous, 1962a,b). The five growth factors were those previously shown to be essential for growth, namely nicotinic acid, inositol, riboflavine, pyridoxal and biotin (Christie \& Porteous, 1962b). The seven L-amino acids were tryptophan, cysteine, serine, glutamic acid, lysine, leucine and isoleucine (Keir \& Porteous, 1962). Ammonium sulphate was absent from the medium $(-)$ or present $(+)$ at an initial concentration of $200 \mu \mathrm{g} / \mathrm{ml}$.

Table 3. Maximum yields of Actinomyces israelii obtained from modifications of medium HP6/B (Keir E Porteous, 1962)

\begin{tabular}{|c|c|c|c|c|c|}
\hline \multirow[b]{2}{*}{ Medium } & \multicolumn{3}{|c|}{ Selected components* } & \multirow{2}{*}{$\begin{array}{l}\text { Total nitrogen } \\
\text { content of the } \\
\text { medium }(\mu \mathrm{g} / \mathrm{ml})\end{array}$} & \multirow{2}{*}{$\begin{array}{l}\text { Maximum } \\
\text { cell yield } \\
(\mu \mathrm{g} \mathrm{N} / \mathrm{ml})\end{array}$} \\
\hline & $\begin{array}{l}\text { Amino } \\
\text { acids }\end{array}$ & $\begin{array}{l}\text { Growth } \\
\text { factors }\end{array}$ & $\begin{array}{l}\text { Purines and } \\
\text { pyrimidines }\end{array}$ & & \\
\hline B & 20 & 16 & - & 655 & 80 \\
\hline B & 20 & 16 & + & 687 & 80 \\
\hline D & 7 & 5 & - & 240 & 70 \\
\hline $\mathrm{F}$ & 7 & 5 & + & 272 & 42 \\
\hline $\mathrm{E}$ & 7 & 16 & - & 240 & 40 \\
\hline
\end{tabular}

*The purines and pyrimidines (adenine, guanine, xanthine, thymine and uracil) were absent from the media $(-)$ or each was present $(+)$ at an initial concentration of $20 \mu \mathrm{g} / \mathrm{ml}$. All media contained ammonium sulphate at an initial concentration of $200 \mu \mathrm{g} / \mathrm{ml}$. The other components are detailed in Table 2.

Table 3 shows the results of further experiments using media all of which now contained ammonium sulphate. The growth obtained in media $\mathrm{A}$ and $\mathrm{B}$ confirmed that the presence or absence of purines and pyrimidines did not affect the stationaryphase cell yields obtained in media containing a full complement of amino acids and growth factors. From the amount of growth obtained in media A, A', C and $\mathrm{C}^{\prime}$ (Table 2) it may be further deduced that purines and pyrimidines were not essential nutrients even when only the five essential growth factors were present. But it is clear (Table 3) that, if the complements of amino acids and growth factors were simultaneously decreased to give medium D, as before (see Table 2) good growth was obtained only if all purines and pyrimidines were absent from the medium; addition of the purines and pyrimidines to medium $\mathrm{D}$ to give medium $\mathrm{F}$ resulted in a severe 
diminution in the maximum cell yield. Separate experiments showed that addition of adenine and thymine to medium $\mathrm{C}^{\prime}$ (Table 2) also severely inhibited growth, suggesting that it was the absence of one or more growth factors rather than the absence of one or more amino acids from medium $D$ that permitted the inhibition of growth by added purines or pyrimidines or both. A similar drastic inhibition of growth was observed when the superfluous growth factors were added to medium $\mathrm{D}$ to give medium E (Table 3).

\section{Conclusions, reservations and predictions}

Within 10 years it has been possible to advance from a situation in which it was difficult to maintain cultures of $A$. israelii to one in which at least one strain will grow vigorously in a medium containing no more than glucose, glutathione, seven L-amino acids (tryptophan, cysteine, serine, glutamic acid, lysine, leucine and isoleucine), five growth factors (nicotinic acid, inositol, riboflavine, pyridoxal and biotin) and a variety of inorganic salts including ammonium sulphate. The key to this advance lies in the pioneering work of Howell \& Pine (1956). It is clear that $A$. israelii is a nutritionally exacting organism not because it requires, as was once supposed, high concentrations or a wide variety of nutrients but because, like many other organisms, it requires a carefully balanced diet. Erikson \& Porteous (1953) suggested that reported failures to maintain cultures of $A$. israelii were due as much to the presence of growth inhibitors in the rich chemically undefined media then in use as to the absence of required nutrients from the media; more recent work would seem to justify that suggestion but it must be emphasized that the detailed results so far available apply to but one typical strain of $A$. israelii. The preliminary survey carried out by Christie \& Porteous $(1962 c)$ has already shown that different strains of the species have different nutrient requirements though the differences may prove to be small when detailed experiments are carried out. It has also to be noted that the work summarized here has not defined the concentrations of various gases (e.g. oxygen and carbon dioxide) which are required or tolerated by the organism; to that extent the growth conditions are not completely defined chemically. Similarly, although the $\mathrm{pH}$ of the growth medium has been monitored with some precision during growth of the organism (Fig. I), no precise information is available on the redox conditions required, produced or tolerated by the organism during growth in any one medium. It also remains to be seen whether there are any distinctive differences between the nutrient requirements of $A$. israelii and of apparently related species such as $A$. bovis (Erikson, I940; Erikson \& Porteous, 1955; Cummins \& Harris, 1958).

Three aspects of the detailed results now available on the nutritional requirements of one strain of $A$. israelii require comment. The first of these concerns the five growth factors required by the organism, the second concerns the amino acids required by the organism and the third concerns the inhibition of growth of the organism under specified conditions by certain major and minor potential nutrients.

It may be asked whether the combination of five growth factors (nicotinic acid, inositol, riboflavine, pyridoxal and biotin) represents the true minimum requirement 
of the organism. Superficially it would seem to be so, but the design of the experiments conducted by Christie \& Porteous ( $1962 b$ ) was such that the apparent requirement for nicotinic acid and inositol was demonstrated by omitting these compounds individually from media containing twenty amino acids and seven or eight other growth factors, four of which were members of the group of five now under discussion. Omission of nicotinic acid or inositol under these circumstances resulted in poor viability of the organism. It is conceivable that nicotinic acid (or inositol or both) were required in these circumstances not to promote growth but to relieve inhibition of growth by one or more of the other growth factors present in the test media. Similar doubts apply, though with less force, to the demonstration by Christie \& Porteous $(1962 b)$ of a requirement for each of the other three growth factors; the apparent requirements for riboflavine, pyridoxal and biotin were demonstrated in media containing no more than six other growth factors, four of which were members of the group of five now under discussion. So long as doubts of this kind remain it is clear that the only acceptable elucidation of the true minimum growth factor requirements of the organism will come from experiments in which every possible combination of one, two, three and four out of five growth factors is tested for its ability to support growth of the organism on specified major nutrients. Only three of the required test media have been examined (Christie \& Porteous, I962 $b$ ); none supported good growth. Confirmation that inositol is in fact a growth factor for A. israelii would be of some importance. There is no doubt that the organism is a true bacterium (Christie \& Porteous, r $962 b$; Cummins \& Harris, 1958) although its morphology is reminiscent of the fungi. Inositol is a well-established micro-nutrient for fungi and some mammalian cells but has not yet been shown unequivocally to be a trace nutrient for any bacterium tested (Knight, I955).

The relatively simple nutritional requirements of the single strain of $A$. israelii examined must imply a greater biosynthetic capacity than has hitherto been suspected. If the biosynthetic mechanisms available to the organism are those known to operate in other organisms then a tentative metabolic map can be drawn up for $A$. israelii. The requirement for L-tryptophan in the growth medium contrasts with the absence of any requirement for phenylalanine, tyrosine or $p$-aminobenzoic acid (Christie \& Porteous, I $962 b$ ) suggesting that the organism is able to convert chorismic acid (Gibson \& Gibson, 1964) into phenylalanine, tyrosine and $p$-aminobenzoic acid but not into tryptophan.

Similarly the fact that $\mathrm{L}$-leucine and $\mathrm{L}$-isoleucine were essential nutrients whereas L-valine was not might suggest that this particular organism is able to condense pyruvic acid with another molecule of pyruvic acid as a step in the synthesis of I.-valine but is unable to carry out the corresponding condensation of pyruvate with $\alpha$-oxobutyrate to form isoleucine; further that although $\mathrm{L}$-valine can be biosynthesized via $\alpha$-oxoisovaleric acid the organism is unable to biosynthesize L-leucine from this precursor (Adelberg \& Rabinovitz, 1956).

It is reasonable to surmise that the tricarboxylic acid cycle is absent from this anaerobic or micro-aerophilic organism or, if present, is unlikely to be able to serve as an adequate source of L-glutamic acid, which proved to be an essential nutrient. As 
neither L-aspartic acid nor L-threonine was a necessary component of the growth medium it may be presumed that they were synthesized at adequate rates via established routes from oxaloacetic acid. The major source of this precursor would presumably be phosphoenolpyruvate (or pyruvate). In contrast, the usual route from phosphoenolpyruvate to serine was apparently not available, since L-serine was an essential nutrient and presumably served also as a source of glycine.

These speculations and those of Christie \& Porteous ( $1962 b$ ) do not exhaust the information available from recent work. They serve only to indicate that it is possible to produce a tentative metabolic map from studies of nutritional requirements; such maps should indicate which branches of metabolism might be most fruitfully investigated. It is perhaps worth emphasizing that the speculations are based upon the quantitative observation of the lag period, the rate of growth and the final cell yield in the simplest medium D (Tables 2 and 3 ; Keir $\&$ Porteous, 1962); in respect of all three measures growth was essentially equivalent to that obtained in more complex media (Fig. 2; Christie \& Porteous, I962a). Monod (1949) and Adelberg \& Rabinovitz ( $195^{6}$ ) have pointed out the dangers inherent in interpreting inadequately defined nutritional data in metabolic terms.

The apparent inability of the Wills strain of $A$. israelii to carry out specific metabolic conversions (as indicated by the above speculations) might be due to the genetically determined absence of the appropriate enzyme, to the inhibition of the enzyme or to the repression of its synthesis under the conditions of culture used. 'The elucidation of these possibilities and of the mechanisms responsible for the marked inhibition of growth by small quantities of purines and pyrimidines or by even smaller quantities of one or more of a group of eleven growth factors (Table 3; Keir $\&$ Porteous, 1962) can come only from detailed metabolic studies. Nutritional studies have yielded nearly all the information that can be expected from them.

Part of the work summarized here was supported by a grant from the Department of Scientific and Industrial Research. The author acknowledges the contributions made to the work by Dr Christie and Mr Keir and thanks Professor Kermack for his support.

\section{REFERENCES}

Adelberg, E. A. \& Rabinovitz, M. (1956). Annu. Rev. Biochem. 25, 349.

Allen, J. M. (editor) (1962). The Molecular Control of Cellular Activity. New York: McGraw-Hill Book Company Inc.

Bergey, D. E. (1957). Manual of Determinative Bacteriology, 7th ed. [R. S. Breed, E. G. D. Murray and N. R. Smith, editors.] Baltimore, Md: The Williams \& Wilkins Company.

Christie, A. O. \& Porteous, J. W. (1960). F. gen. Microbiol. 23, $26 \mathrm{I}$.

Christie, A. O. \& Porteous, J. W. (1962a). Y. gen. Microbiol. 28, 443.

Christie, A. O. \& Porteous, J. W. (1962b). \%. gen. Microbiol. 28, 455.

Christie, A. O. \& Porteous, J. W. (1 962c). Nature, Lond., 195, 408.

Cummins, C. S. \& Harris, H. (1958). F. gen. Microbiol. 18, 173.

Davis, B. D. (1955). Advanc. Enzymol. 16, 247.

DeBusk, A. G. (1956). Advanc. Enzymol. 17,393.

Demerec, M. \& Hartman, P. E. (1959). Annu. Rev. Microbiol. 13, 377.

Erikson, D. (1935). Spec. Rep. Ser. med. Res. Coun., Lond., no. 203.

Erikson, D. (1940). Spec. Rep. Ser. med. Res. Coun., Lond., no. 240.

Erikson, D. (1949). Annu. Rev. Microbiol. 3, 23. 
Erikson, D. (1953). Int. Congr. Microbiol. Symp. Actinomycetales, p. 102.

Erikson, D. \& Porteous, J. W. (1953). F. gen. Microbiol. 8, 464.

Erikson, D. \& Porteous, J. W. (1955). F. gen. Microbiol. 13, 26 r.

Frisch, L. (editor) (1961). Cold Spr. Harb. Symp. quant. Biol. 26.

Gibson, M. I. \& Gibson, F. (1964). Biochem. F. 90, 248.

Howell, A. \& Pine, L. (1956). F. Bact. 71, 47.

Howell, A., Stephan, R. M. \& Paul, F. (1962). F. dent. Res. 41, $105^{\circ}$.

Jacob, F. \& Monod, J. (I961). F. mol. Biol. 3, 318.

Jensen, H. L. (1953). Int. Congr. Microbiol. Symp. Actinomycetales, p. 69.

Keir, H. A. \& Porteous, J. W. (1962). F. gen. Microbiol. 28, 193.

Knight, B. C. J. G. (1955). F. gen. Microbiol. 12, 348 .

Knox, W. E., Auerbach, V. H. \& Lin, E. C. C. (1956). Physiol. Rev. 36, 164.

Krebs, H. A. (1956). In Ciba Foundation Symposium on Ionizing Radiations and Metabolism. London: Churchill.

Lichstein, H. C. (1960). Annu. Rev. Microbiol. 14, 17.

Monod, J. (r949). Annu. Rev. Microbiol. 3, 371.

Monod, J. \& Jacob, F. (1961). Cold Spr. Harb. Symp. quant. Biol. 26, 389.

Pontecorvo, G. (1963). Proc. roy. Soc. B, 158, I.

Riley, M. \& Pardee, A. B. (r 962). Annu. Rev. Microbiol. 16, I.

Weber, G. (editor) (1963). Advances in Enzyme Regulation. Vol. r. Oxford: Pergamon Press Ltd.

Wolstenholme, G. E. W. \& O'Connor, C. M. (editors) (1959). Ciba Foundation Symposium on the Regulation of Cell Metabolism. London: Churchill.

\section{Sulphate metabolism of moulds}

\section{By Marvin J. Johnson, Department of Biochemistry, University of Wisconsin, Madison, Wisconsin}

Most micro-organisms are able to use sulphate ion as a sole source of sulphur. During the last decade, much has become known about the mechanism of conversion of sulphate ion into sulphur amino acids and other organic sulphur compounds. Much more remains to be learned.

I should like to discuss some aspects of intermediary sulphur metabolism of microorganisms in general, and of moulds in particular. Our laboratory first became interested in the sulphur metabolism of moulds through our work on penicillin formation. Tardrew \& Johnson ( 1958 ) noted that a number of Penicillium chrysogenum mutants, selected for their ability to give high yields of penicillin, had an abnormal sulphur metabolism. They used about four times as much inorganic sulphate as unmutated strains, and produced about four times as much organic sulphur, even under conditions where penicillin production was low. Segel \& Johnson (I96I) showed that these strains had a much higher level of intracellular inorganic sulphate than normal strains. During growth of mycelium, the intracellular inorganic sulphate concentration reached $0.028 \mathrm{M}$, while the extracellular sulphate level was $0.005 \mathrm{M}$. The actual intracellular sulphate was higher than $0.028 \mathrm{M}$, because in our calculation we assumed that all of the water in the washed, blotted mycelium was inside the cells. The intracellular sulphate level of the unmutated strain, grown under similar conditions, at similar extracellular sulphate concentrations, was less than $0.005 \mathrm{M}$.

We decided to do further work on the mutated strain. We grew the mycelium on a mineral medium in which the sulphate content was low, but not low enough to limit growth. Then carrier-free radioactive sulphate was added and, after various time periods, measured in sec, a sample of the mycelium was quickly filtered and inactivated with boiling water. Before discussing the results of these experiments, it is $23(2) 7$ 